\title{
Acoustic rhinometry after nasal provocation test, 6 months interim analysis of alumites study, a randomized, controlled, multicentre phase IV study with house dust mites subcutaneous immunotherapy
}

\author{
Jaime Sanchez ${ }^{1 *}$, Carmen Vidal ${ }^{2}$, Dolores Hernandez ${ }^{3}$, Antonio Valero ${ }^{1}$, Jose Vicente Castello ${ }^{4}$, Antonio Pelaez ${ }^{5}$, \\ Mario Alberto Garcia ${ }^{6}$
}

From 9th Symposium of Experimental Rhinology and Immunology of the Nose (SERIN 2013) Leuven, Belgium. 21-23 March 2013

\section{Background}

ALUMITES study was designed to assess the efficacy of house dust mites (HDM: D. pteronyssinus $+D$. farinae) subcutaneous immunotherapy for the treatment of allergic rhinitis patients along one year. Here we report an interim analysis done after 6 months of treatment.

\section{Methods}

In this controlled multicentre phase IV study, HDM adult allergic patients were randomized to receive subcutaneous immunotherapy with a $10 \mathrm{IR} / \mathrm{ml}$ depot extract plus symptomatic treatment (group A) or only symptomatic treatment (group B) (2:1). Acoustic rhinometry after nasal provocation test (NPT) was selected to objectively assess the efficacy of this treatment by measuring the nasal volume (NV) and minimum cross-sectional area (MCA). A visual analogic scale (VAS) has been used to subjectively assess the efficacy (0-10 scale, lower is better)NPT consists in 5 determinations at intervals of 15 minutes (basal, diluent, $0.01 \mathrm{IR}, 0.1 \mathrm{IR}, 1$ IR) and one last determination 30 minutes after the last administration. The extract used for the NPT was 100 $\mathrm{IR} / \mathrm{ml}$ of $D$. pteronyssinus.

\section{Results}

Data from 38 of 57 patients were complete to be analyzed. MCA difference from baseline to six months visit

${ }^{1}$ Hospital Clinic Universitari de Barcelona, Allergy Service, Barcelona, Spain Full list of author information is available at the end of the article was $1.6 \mathrm{~cm}^{2}$ (95\% CI: $\left.[-2.1,5.3]\right)$ in active group and 0.8 $\mathrm{cm}^{2}$ (95\% CI: $\left.[-4.3,5.9]\right)$ in control group. NV difference from baseline to six months visit was $37.1 \mathrm{~cm}_{3}(95 \% \mathrm{CI}$ : $[-16.9,91.2])$ in active group and $-5.8 \mathrm{~cm} 3(95 \% \mathrm{CI}$ : $[-75.6,64])$ in control group. The analysis of covariance (ANCOVA) showed statistical differences in basal determination of MCA after 6 months treatment $(\mathrm{p}=0.0001)$. The symptoms score after the last provocation of 1 IR measured by VAS from baseline to the six month visit had a reduction of -2.4 points $(95 \%$ CI: $[-3.2,-1.6]$, $\mathrm{p}<0.0001)$ in the active group whereas there was no statistical reduction in the control group: -0.7 points $(95 \%$ CI: $[-2.5,1.0], \mathrm{p}=0.577)$.

\section{Conclusion}

Despite of the final low sample to analyze, efficacy is demonstrated with six months of SCIT treatment with $10 \mathrm{IR} / \mathrm{ml}$ depot HDM extract that resulted in a significant improve in clinical symptoms, this improvement was not achieved by the control group. Objective assessment of efficacy shows a clear positive trend in minimal cross-sectional area determination.

\section{Author details}

Hospital Clinic Universitari de Barcelona, Allergy Service, Barcelona, Spain. ${ }^{2}$ Complejo Hospitalario de Santiago. Hospital del Conxo, Allergy Service, Santiago de Compostela, Spain. ${ }^{3}$ Hospital Universitario y Politecnico La Fe, Allergy Service, Valencia, Spain. ${ }^{4}$ Hospital General de Castellon, Allergy Service, Castellon, Spain. ${ }^{5}$ Hospital Clinico Universitario de Valencia, Allergy Service, Valencia, Spain. ${ }^{6}$ Stallergenes Iberica, Medical Department, Barcelona, Spain. 


\section{doi:10.1186/2045-7022-3-S2-P43}

Cite this article as: Sanchez et al:: Acoustic rhinometry after nasal provocation test, 6 months interim analysis of alumites study, a randomized, controlled, multicentre phase IV study with house dust mites subcutaneous immunotherapy. Clinical and Translational Allergy 2013 3(Suppl 2):P43.

Submit your next manuscript to BioMed Central and take full advantage of:

- Convenient online submission

- Thorough peer review

- No space constraints or color figure charges

- Immediate publication on acceptance

- Inclusion in PubMed, CAS, Scopus and Google Scholar

- Research which is freely available for redistribution

Submit your manuscript at www.biomedcentral.com/submit
Ciomed Central 